\title{
Personality Traits As Predictors Of Burnout Syndrome Among Nurses In The University Of Port Harcourt Teaching Hospital Rivers State
}

\author{
Dr. R. O. Ekechukwu \\ Department of Educational Psychology, Faculty of Education, \\ University of Port Harcourt, Rivers State, Nigeria. \\ Osuagwu Isabella \\ Institution of Education , Faculty of Education, \\ University of Port Harcourt, Rivers State, Nigeria.
}

\begin{abstract}
The study investigated personality traits as predictors of burnout syndrome among nurses in the University of Port Harcourt Teaching Hospital Rivers State. The study used the correlational research design. The population of the study comprised of all 750 nurses in the University of Port Harcourt Teaching Hospital. A sample of $\mathbf{3 0 0}$ nurses from Paediatrics Ward, Male Ward, Female Ward and Intensive Care Unit (ICU), were randomly selected using the simple random sampling technique (balloting). Two instruments titled; Maslach Burnout Scale (MBS) by Maslach (1996) and Personality Inventory (NEO) by Costa and McCrae (1992) were used to collect data for the study. The Cronbach Alpha reliability was used to establish the internal consistency reliability coefficients of 0.87 and 0.81 respectively. Responses to the research questions were analyzed with mean and standard deviation, while the hypotheses will be tested with multiple regression associated with independent sample t-test statistics. The findings of the study revealed that personality traits (neuroticism, extraversion, openness to experience) jointly predict burnout syndrome among nurses in University of Port Harcourt Teaching Hospital. Further analysis of the result showed that when personality traits of neuroticism, extraversion, openness to experience where looked at independently, only neuroticism and extraversion relate significantly predict burnout syndrome while openness to experience did not. Based on the findings of the study it was recommended among others that counsellors, psychologists and others in the helping profession should readily offer practical assistance to nurses experiencing burnout to enable them cope with the stressful experience they encounter in their daily work assignments.
\end{abstract}

Keywords: Personality traits (Neuroticism, Extraversion, Openness to experience) and Burnout syndrome.

\section{INTRODUCTION}

In today's technological and moving business world, a significant number of persons work in formal organizations and under various conditions. Some persons work indoors, others work outside. Some jobs require exposure to intense heat, cold, noise, high risk, and injury whereas others carry low risks, and so does the work schedule and time varies. The average working time in the civil service, public and/or private sector encompasses a major part of the individual's life span and occupies a period when physical and mental capacities are fully utilized. A profession like nursing demands 24-hours service delivery a day, increased workload, and exposure to long-hours of stressors. It has been argued that nurses continuing exposure to stressors results in a psychophysical condition called burnout syndrome. Burnout has been defined as a syndrome of physical and emotional exhaustion, involving the 
development of stress which can lead to the development of negative self-concept, negative job attitudes and loss of concern for clients (Abushaikha \& Saca-Hazboun, 2009).

The term 'burnout' was coined in the 1970s to describe the physical and emotional exhaustion that workers may experience on the job, especially those who provide some type of service to others (Irving, Dobkin\& Park, 2009). Robinson, Ode and Hilmert (2011) described burnout as a situation in which workers are continuously subjected to stressors that they find themselves unable to cope with, which in turn makes them feel exhausted, lacking in energy, and mentally fatigued. Maslach and Jackson as cited in Guillermo, Elena, Lucia and Emilia (2018), described burnout as comprising three dimensions; (1) emotional exhaustion, characterized by lack of energy and enthusiasm and depletion of emotional resources; (2) depersonalization, described as negative attitudes toward clients, colleagues, and the organization; and (3) reduced personal accomplishment, which is manifested as a worker's tendency towards negative self-evaluation, showing dissatisfaction with their own performance at work. Burnout has also been associated with high employment turnover, excessive absenteeism, negative job attitudes, low morale and a reduction in willingness to help others (Abushaikha\&Saca-Hazboun, 2009).Burnout is a specific kind of occupational stress among human service professionals, as a result of the demanding and emotionally charged relationships between caregivers and their recipients (Maslach, 2011).

Nurses are considered to be particularly susceptible to the danger of burnout, due to the very stressful nature of their work, which has a negative impact on their mental and physical health, efficacy and productivity (Gil-Monte, 2005; Hudek-Knežević, Kalebić \& Krapić, 2011). A nurse's job is predominantly emotional, and this factor is considered as a main stressor, which can result in a direct intention to leave work (Bartram, Casimir, Djurkovic \& Leggat, 2012). The role of nurses has long been regarded as stress-filled based upon the physical labor, human suffering, work hours, staffing, and interpersonal relationships that are central to what the work nurses do (Lukpata, Lukpata, Ndiok \& Mgbekem, 2013). This stressful nature of the nursing profession can ultimately lead to job dissatisfaction and burnout (Arafa, 2003).

Nursing occupies a conspicuous position among the professions that have been identified as the most stressful worldwide as nurses relate with humans mostly in times of pain, suffering and death (Lukpata, Lukpata, Ndiok \& Mgbekem, 2013). Rowe (2003) stressed that nurses work tirelessly rendering care to critically and chronically ill patients who are between life and death in an environment where there is lack of tolerance for error, and this exert intense psychological and physical pressures on the health caregiver leading to burnout syndrome. To further buttress this, Abushaikha and Saca-Hazboun (2009) explained that among health care professionals, nurses are the most prone to burnout because are expected to deliver humane, empathetic, culturally sensitive, proficient and moral care, in working environments with limited resources, reduced supply of nurses and increasing responsibilities. Such imbalance between providing high quality care within an environment of limited resources leads to burnout (Khamisa, Oldenburg, Peltzer \& Ilic, 2015).

Symptoms of burnout syndrome among nurses are nonspecific and include tiredness, headaches, eating problems, insomnia, irritability, emotional instability and rigidity in relationships with other people (Kilikova \&Sramka, 2006). Other symptoms include low quality of care for patients, outburst of anger, increased error rate, suicidal thoughts and suicide, substance use and abuse (Rakovan \& Kacmarova, 2014). Some behavioural impact of burnout syndrome include reduced level of job performance, errors of judgement, diminished interest in social activities, feelings of detachment from others, irresponsibility, low morale, absenteeism, early retirement and quitting the nursing altogether (Jaramillo, 2005).This apt 
description indicates that, nurses experiencing burnout syndrome usually have impaired mental health functioning as well as poor physical health (Zayfart, 2002). Sequel to this, it is imperative that this study investigate personality traits as predictors of burnout syndrome among nurses in Teaching Hospital of Rivers State.

Personality traits are conceptualized as dimensions of individual differences in tendencies to show consistent patterns of thoughts, feelings, and actions across events, developmental periods and contexts (McCrea \& Costa, 2003). There are debate that personality traits such neuroticism, extraversion and openness to experience may relate to burnout syndrome among nurses. Several studies on the Neo personality dimensions derived from Eysencks' model of personality have maintained that, neuroticism which is one of the Neo- personality traits, describes a tendency to react with strong emotion to adverse events. Individuals who are high on this dimension (neuroticism) are more sensitive to stress because their responses are more rapid, more intense and slower to return to baseline. Conversely, those who are low on neuroticism traits find it easier to "shake off" stressful events (Paris, 2000).

In a cross-sectional study conducted on a group of nurses, Allen and Mellor (2002) found out that neuroticism had a significant relationship with burnout symptoms such as emotional exhaustion, depersonalization and reduced personal accomplishment. Extraversion is characterized by being outgoing, social, talkative and interactive (Ereiga, Gideon, Ojo \& Abiodun, 2014). It shows personal traits such as sociability, friendliness and easy-going. In jobs that require social skills (like nursing) extraversion has key role in job performance (Worsfold, as cited in Sahar, Najme, Abolghassem \& Hamid, 2009).

Openness has been defined as a way of relating to the world through active imagination, aesthetic sensitivity, attentiveness to feelings, preference for variety, and intellectual curiosity (Costa \& McCrae, 2000). Openness to experience operates as a protective factor at the individual level in the face of potentially traumatic events. Individuals who are low on openness to experience personality tend to be more sensitive to stress and any anxiety provoking events. Meanwhile, those who are high on openness to experience personality develop resistance to the development of burnout (Zellars, Perrewe \& Hochwarter, 2000).

It has been observed that nurses are exposed to various stressful situations which impact negatively on their health and performance. The nature of the nursing profession requires that nurses are constantly on alert whether on or off duty, attending to sick patients and this has taken a toll on the nurses' health, emotions, interpersonal relationships and level of resilience. Burnout due to exposure to stressful work environments among nurses has resulted in negative physiological and psychological consequences like headache, muscular tensions, fatigue, irritability, insomnia, depression, hypertension and suicide among nurses. Burnout has led to negative behavioural reactions such as reduced level of job performance, errors of judgement, irresponsibility, low morale, absenteeism, tardiness, early retirement and quitting the nursing profession. Burnout has also resulted in isolation, excessive drinking and smoking, alcoholism and drug abuse. Some nurses experience job dissatisfaction as such they would absent themselves from duties without permission from their superiors or formally request for leave of absence from work. Therein, this study investigated personality traits as predictors of burnout syndrome among nurses in University of Port Harcourt Teaching Hospital in Rivers State, Nigeria.

\section{Aim and Objectives of the Study}

The study examined personality traits as predictors of burnout syndrome among nurses in University of Port Harcourt Teaching Hospital. Specifically, the study sought to; 
1. Determine the extent to which personality traits (neuroticism, extraversion, openness to experience) jointly predict burnout syndrome among nurses in University of Port Harcourt Teaching Hospital.

2. Determine the extent to which personality traits (neuroticism, extraversion, openness to experience) independently predict burnout syndrome among nurses in University of Port Harcourt Teaching Hospital.

\section{Research Questions}

The following research questions guided the study;

1. To what extent does personality traits (neuroticism, extraversion, openness to experience) jointly predict burnout syndrome among nurses in University of Port Harcourt Teaching Hospital?

2. To what extent does personality traits (neuroticism, extraversion, openness to experience) independently predict burnout syndrome among nurses in University of Port Harcourt Teaching Hospital?

\section{Hypotheses}

The following hypotheses which were tested at 0.05 level of significance guided the study;

1. Personality traits (neuroticism, extraversion, openness to experience) do not jointly predict burnout syndrome among nurses in University of Port Harcourt Teaching Hospital.

2. Personality traits (neuroticism, extraversion, openness to experience) do not independently predict burnout syndrome among nurses in University of Port Harcourt Teaching Hospital.

\section{METHODOLOGY}

The study used the correlational research design. The population of the study comprised of all 750 nurses in the University of Port Harcourt Teaching Hospital. A sample of 300 nurses from Paediatrics Ward, Male Ward, Female Ward and Intensive Care Unit (ICU), were randomly selected using the simple random sampling technique (balloting). Two instruments titled; Maslach Burnout Scale (MBS) by Maslach (1996) and Personality Inventory (NEO) by Costa and McCrae (1992) were used to collect data for the study. The instruments were designed on a four point Likert scale of Strongly Agree (SA) =4, Agree (A) =3, Disagree (D) =2, and Strongly Disagree $(S D)=1$. The Cronbach Alpha reliability was used to establish the internal consistency reliability coefficients of 0.87 and 0.81 respectively. Responses to the research questions were analyzed with mean and standard deviation, while the hypotheses will be tested with multiple regression associated with independent sample t-test statistics.

\section{RESULTS AND DISCUSSION}

Research Question 1: To what extent does personality traits (neuroticism, extraversion, openness to experience) jointly predict burnout syndrome among nurses in University of Port Harcourt Teaching Hospital?

Hypothesis 1: Personality traits (neuroticism, extraversion, openness to experience) do not jointly predict burnout syndrome among nurses in University of Port Harcourt Teaching Hospital

Table 1: Regression analysis on the extent personality traits (neuroticism, extraversion, openness to experience) jointly predict burnout syndrome among nurses

Model $\quad$ R $\quad$ R Square Adjusted R Square Std. Error of the

Estimate 
From the result of the above table, the correlation coefficient $(r=0.889)$ of the joint prediction of personality traits (neuroticism, extraversion, openness to experience) and burnout syndrome is strong and positive. The coefficient of determination $\left(\mathrm{r}^{2}=0.790\right)$ indicates that $79 \%$ of burnout syndrome can be jointly explained by personality traits. Therefore the null hypothesis was rejected. This thus implies that personality traits (neuroticism, extraversion, openness to experience) jointly predicts burnout syndrome significantly among nurses in University of Port Harcourt Teaching Hospital.

Research Question 2: To what extent does personality traits (neuroticism, extraversion, openness to experience) independently predict burnout syndrome among nurses in University of Port Harcourt Teaching Hospital?

Hypothesis 2: Personality traits (neuroticism, extraversion, openness to experience) do not independently predict burnout syndrome among nurses in University of Port Harcourt Teaching Hospital

Table 2: Beta and t-test analysis on the independent prediction of personality traits (neuroticism, extraversion, and openness to experience) on burnout syndrome Explained Variable Unstandardized standardized Coefficients Coefficients

\begin{tabular}{lccccc} 
& B & Std.Error & Beta & t & P-value \\
\hline (Constant) & 22.626 & 3.027 & & 7.056 & 0.000 \\
\hline Neuroticism & 0.202 & 0.085 & 0.132 & 2.380 & 0.018 \\
\hline Extraversion & 0.406 & 0.079 & 0.185 & 5.121 & 0.000 \\
\hline $\begin{array}{l}\text { Openness to } \\
\text { Experience }\end{array}$ & 0.049 & 0.078 & 0.035 & 0.632 & 0.528 \\
\hline
\end{tabular}

Dependent Variable: Burnout Syndrome

Table 2 shows that unstandardized coefficients (B) obtained for the personality factors of neuroticism, extraversion and openness to experience are $0.202,0.406$, and 0.049 respectively while that of constant is 22.626. Hence, the multiple regression model is $\mathrm{Y}=22.626+0.202 \mathrm{X}_{1}+$ $0.406 \mathrm{X}_{2}+0.049 \mathrm{X}_{3}$ where $\mathrm{Y}$ is the predictor value of burnout syndrome then $\mathrm{X}_{1}, \mathrm{X}_{2}$, and $\mathrm{X}_{3}$ refers to any given value of neuroticism, extraversion and openness to experience.

The table also shows that the beta value for neuroticism is 0.132 while its associated $t$-value is 2.38 significant at $p$-value of 0.018 . The fact that 0.018 level is lower than 0.05 the chosen level of probability is then deduced that neuroticism significantly predict burnout syndrome. Considering the personality trait of extraversion, the beta value obtained is 5.121 and it is significant at 0.000 level. The fact 0.000 level is lower than 0.05 , the chosen level of probability $(\mathrm{P}<0.05)$, then extraversion significantly predict burnout syndrome. The beta value obtained for openness to experience is 0.035 while its associated t-value is 0.632 which is significant at 0.528 level $(\mathrm{P}>0.05)$. Hence, openness to experience does not significantly predict burnout syndrome among nurses in University of Port Harcourt Teaching Hospital. Finally, considering the beta values of these personality trait of neuroticism $=0.132$, extraversion $=0.185$ and openness to experience $=0.035$, it could be deduced that extraversion had the highest prediction on burnout syndrome, followed by neuroticism and then openness to experience.

\section{SUMMARY OF FINDINGS}

The results obtained after data analysis are summarized below;

1. The study showed that personality traits (neuroticism, extraversion, openness to experience) jointly predicts burnout syndrome significantly among nurses in University of Port Harcourt Teaching Hospital in Rivers State. 
2. Neuroticism and extraversion personality traits independently predict burnout syndrome significantly among nurses in University of Port Harcourt Teaching Hospital whereas openness to experience did not.

\section{DISCUSSION OF FINDINGS OF THE STUDY \\ Personality Traits and Burnout Syndrome}

The result of the study showed that personality traits (neuroticism, extraversion, openness to experience) jointly predicts burnout syndrome significantly among nurses in University of Port Harcourt Teaching Hospital in Rivers State. Further analysis of the result showed that neuroticism and extraversion independently predict burnout syndrome significantly among nurses in University of Port Harcourt Teaching Hospital whereas openness to experience did not. The findings of this study is in agreement with an earlier study by Allen and Mellor (2002) who found out that neuroticism and extraversion personality traits had a significant relationship with burnout symptoms such as emotional exhaustion, depersonalization and reduced personal accomplishment while openness to experience did not. Stein (2012) found out personality traits significantly predicts burnout syndrome among health workers and that those who are high on neuroticism personality trait lack or have inadequate social skills needed in varied social situations and this feeling of inadequacy consequently cause them to fear social situations, avoid them and experience burnout. Paris (2000) also found out that people who are high on neuroticism trait tend to be nervous, suffer from high levels of worry, are emotional and insecure, have feelings of inadequacy and are vulnerable to burnout. Conversely, those who are low on neuroticism trait find it easier to shake off stressful events and unfamiliar situations.

Gilbert (2001) found out that those who are high on extraversion personality trait are very sociable, interactive and assertive hence they are less likely to develop burnout, whereas people who are low on extraversion personality trait are at high risk of developing burnout syndrome. He further stressed that those who are high on openness to experience personality trait develop resistance to the development of burnout hence, openness to experience personality trait does not predict burnout syndrome.

\section{CONCLUSION}

Nurses are exposed to various stressful situations which impact negatively on their health and performance. The nature of the nursing profession requires that nurses are constantly on alert whether on or off duty, attending to sick patients and this has taken a toll on the nurses' health, emotions, interpersonal relationships and level of resilience. Burnout due to exposure to stressful work environments among nurses has resulted in negative physiological and psychological consequences like headache, muscular tensions, fatigue, irritability, insomnia, depression, hypertension and suicide among nurses. Burnout has led to negative behavioural reactions such as reduced level of job performance, errors of judgement, irresponsibility, low morale, absenteeism, tardiness, early retirement and quitting the nursing profession. This study has showed that personality traits (neuroticism, extraversion, openness to experience) jointly predicts burnout syndrome significantly among nurses in University of Port Harcourt Teaching Hospital in Rivers State.

\section{RECOMMENDATIONS}

Based on the findings of this study, the researcher recommended the following;

1. Counsellors, psychologists and others in the helping profession should readily offer practical assistance to nurses experiencing burnout to enable them cope with the stressful experience they encounter in their daily work assignments. 
2. The duties assigned to nurses should though be challenging, but moderate and should not exert excessive physical and psychological pressure on nurses in order to help them cope with the demand of their duties.

\section{References}

Abushaikha, L. \& Saca-Hazboun, H. (2009). Job satisfaction and burnout among Palestinian nurses. Eastern Mediterranean Health Journal, 15, 190-197.

Allen, J., \& Mellor, D. (2002). Work context, personal control and burnout among nurses. Western Journal of Nursing Research, 24(8), 905-917.

Arafa, M.A. (2003). Predictors of psychological well-being of nurses in Alexandria, Egypt. International Journal of Nursing Practice, 9, 313-320.

Bartram, T., Casimir, G., Djurkovic, N., Leggat, G. S. (2012). Do perceived high performance work systems influence the relationship between emotional labour, burnout and intention to leave? A study of Australian nurses. Journal of Advanced Nursing, 68(7), 67-78.

Costa, P.T., \& McCrae, R.R. (2000). Professional manual: Revised NEO Personality Inventory (NEO-PI-R) and NEO Five-Factor Inventory (FFI) professional manual. Lutz, FL: Psychological Assessment Resources, Inc.

Ereiga, E. G., Gideon, I. C. Ojo, T. T., \& Abiodun, W. A. (2014). Personality and demographic factors as correlates of post-traumatic stress disorder among flood victims. British Journal of Education, 2 (3) 82-88

Gil-Monte, P. (2005). Factorial validity of the Maslach Burnout Inventory (MBI-HSS) among Spanish professionals. Rev Saude Publica, 39 (1), 1-8

Guillermo, C. D., Elena, O., Lucia, R. B., \& Emilia, D. F. (2018). Gender, marital status and children as risk factors for burnout in nurses: A meta-analytic study. International Journal of Environmental Research and Public Health, 15(10), 1-13.

Hudek-Knežević, J., Kalebić, B. M., \& Krapić, N. (2011). Personality, organizational stress and attitudes toward work as prospective predictors of professional burnout in hospital nurses. Croatian Medical Journal, 52(4), 38-49.

Irving, J.A., Dobkin, P.L. \& Park, J. (2009). Cultivating mindfulness in healthcare professionals: A review of empirical studies of Mindfulness-Based Stress Reduction (MBSR). Complementary Therapies in Clinical Practice, 15, 61-66.

Khamisa, N., Oldenburg, B., Peltzer, K. \& Ilic, D. (2015). Work related stress, burnout, job satisfaction and general health of nurses. International Journal of Environmental Research and Public Health, 12, 652-666.

Kilikova, M., \& Sramka, M. (2006). Causes and consequences of the burnout syndrome in healthcare. Nursing Horizon, 3(3), 94-96

Lukpata, F.E., Lukpata, O.H., Ndiok, A. \& Mgbekem, M.A. (2013). Nurses workplace stress and patient safety in General Hospital Calabar, Cross River State, Nigeria. International Professional Nursing Journal, 11, 87-92.

Maslach, C. (2011). Engagement research: Some thoughts from a burnout perspective. European Journal of Work and Organizational Psychology, 20 (1), 47-52

McCrae, R. R., Costa, P. T. (2003). Personality in adulthood: A five-factor theory perspective (2nd ed.). New York:Guilford Press.

Paris, J. (2000) Predispositions, personality traits and posttraumatic stress disorder. Harv Rev Psychiatry 8(4):175-83.

Rakova, J., \& Kacmarova, L. (2014). Analysis of selected indicators in the context of health and social care for seniors. In Szyska M et al. (eds.) International and non-institutional forms of support for older people 239-251

Robinson, M.D., Ode, S. \& Hilmert, C. (2011). Regulated and unregulated forms of cortisol reactivity: A dual vulnerability model. Psychosomatic Medicine, 73, 250-256.

Rowe, J. (2003). The suffering of the healer. Nursing Forum, 38, 16-20.

Sahar, J. G., Najme, O. A., Abolghassem, N., \& Hamid, R. O. (2009). The relationship of personality characteristics and burnout among nurses. Iranian Journal of Nursing and Midwifery Research, 14(4), 190-194.

Stein, C., \& Sibanda, T. (2012). Burnout among paramedic students at a university in Johannesburg, South Africa. Ajhpe, 8(2), 142-145 
Ekechukwu, R. O., \& Isabella, O. (2020). Personality Traits As Predictors Of Burnout Syndrome Among Nurses In The University Of Port Harcourt Teaching Hospital Rivers State. Advances in Social Sciences Research Journal, 7(3) 35-42.

Zayfart, C., Becker, C. B., Unger, D. L., \& Shearer, D. K. (2002). Comorbid anxiety disorders in civilians seeking treatment for PTSD. Journal of Traumatic Stress, 15, 31-38

Zellars, K. L., Perrewe, P. L., \& Hochwarter, W. A. (2000). Burnout in health care: The role of the five factors of personality. Journal of Applied Social Psychology, 30, 1570-1598. 